\title{
CORRECTION
}

\section{Correction to: Cannabinoids, TRPV and nitric oxide: the three ring circus of neuronal excitability}

\author{
Giuditta Gambino $^{1}\left(\mathbb{0} \cdot\right.$ Valerio Rizzo $^{1} \cdot$ Giuseppe Giglia $^{1} \cdot$ Giuseppe Ferraro $^{1} \cdot$ Pierangelo Sardo $^{1}$
}

Published online: 11 December 2019

(c) Springer-Verlag GmbH Germany, part of Springer Nature 2019

\section{Correction to: Brain Structure and Function https://doi.org/10.1007/s00429-019-01992-9}

In the original publication of the article, the names of the authors were incorrectly swapped as Gambino Giuditta, Rizzo Valerio, Giglia Giuseppe, Ferraro Giuseppe, Sardo Pierangelo.

The correct author list is as follows:

Giuditta Gambino, Valerio Rizzo, Giuseppe Giglia, Giuseppe Ferraro, Pierangel Sardo.

The original article has been corrected.

The original article can be found online at https://doi.org/10.1007/ s00429-019-01992-9.

\section{Giuditta Gambino} giuditta.gambino@unipa.it

1 Department of Experimental Biomedicine, Neuroscience and Advanced Diagnostics (Bi.N.D.), Sezione di Fisiologia Umana G. Pagano, University of Palermo, Corso Tukory 129 , Palermo, Italy 